\title{
Spontaneous fracture of indwelling polyurethane ureteral stents: A case series and review of literature
}

\author{
Michael E. Chua, MD; Marcelino L. Morales Jr, MD \\ St. Luke's Medical Center, Institute of Urology, Quezon City, Philippines
}

Cite as: Can Urol Assoc J 2012;6(5):386-92. http://dx.doi.org/10.5489/cuaj.12013

\section{Abstract}

Polyurethane, due to its low cost, high versatility and availability, it commonly used for ureteral stents. Spontaneous fracture of these stents is rare, and the most dreaded complication. We present four cases of spontaneous fracture of indwelling polyurethane ureteral stents and review the literature to identify potential factors and preventive strategies.

\section{Introduction}

Since $1967,{ }^{1}$ the indwelling ureteral stent has become a fundamental part of urology practice in an era of expanding endourological procedures. Ureteral stents are used in a variety of indications for renal transplantation, genitourinary oncology, trauma and reconstructive surgeries. ${ }^{2}$ Polyurethane, due to its low cost, high versatility and availability, is commonly used for ureteral stents. Since its introduction, complications had been encountered and resulted in significant morbidity. Pain, bladder irritative symptoms and fever are signs of early complications related to polyurethane ureteral stents; moreover, late complications, such as encrustation, infections and fragmentation, are more troublesome. ${ }^{3-6}$ Cases of fragmented ureteral stents are rare ${ }^{7-15}$ and are classified as grade 3 on the Clavien Classification of Surgical Complications. ${ }^{16}$ We present 4 cases of spontaneous polyurethanene ureteral stent fragmentation and review the literature to generate a summary for its risk factors as well as preventive strategies.

\section{Case 1}

A 31-year-old female with no known medical comorbidities consulted at our outpatient clinic due to stenturia. Five months earlier, she had two Fr $6 \times 26-\mathrm{cm}$ Tecoflex polyurethane double pigtail ureteral stents (R\&D Tech Inc., Groton,
MA) inserted bilaterally for temporary relief of post-intracorporeal lithotripsy ureteral edema on the left and for ureteral healing on the right post-ureterolithotomy. We requested a follow-up for J stent removal within a month, however, she was lost to follow-up.

Now, she presented with gross hematuria, concomitant right flank pain and occasional dysuria. On physical examination revealed low grade fever $\left(38^{\circ} \mathrm{C}\right)$, with right costovertebral angle tenderness, other systemic examination was unremarkable. Routine biochemical parameters were normal: urinalysis revealed proteinuria (300 mg/dL), leukocyte esterase positive $(+3)$; hematuria red blood cells (RBC) (3825/hpf) and bacteruria (300/hpf). Urine culture requested revealed Enterococcus sp about $40000 \mathrm{cfu} / \mathrm{mL}$. A computed tomography (CT) stonogram showed an indwelling left ureteral stent in place and a retained fragmented piece at the right pelvis (Fig. 1), while dilated pelvocalyceal system of the right kidney was noted with perinephric fat stranding. She was hospitalized, started culture-guided intravenous (IV) antibiotics and underwent cystoscopy and J stent on the left ureter; these were uneventful. Retrieval of stent fragment on the right was done video-assisted using Fr 9 semi-rigid ureteroscope with the patient placed on lithotomy Fowler's position. On ureteroscopy, the ureteral mucosa on the right proximal segment of the ureter appeared edematous and erythematous. Using a ureteral foreign body grasper, we removed the stent fragment under direct visualization on the camera monitor. Right ureteral intubation was then done to alleviate the ureteral edema. No serious complications were noted (Table 1). Open ureteral catheter was removed after 72 hours. The patient recovered well and discharged on postoperative day (POD) 4.

\section{Case 2}

A 62-year-old male, known hypertensive non-diabetic, consulted at our outpatient clinic for cystoscopy J stent removal after 6 months of indwelling. Before the insertion, he was 


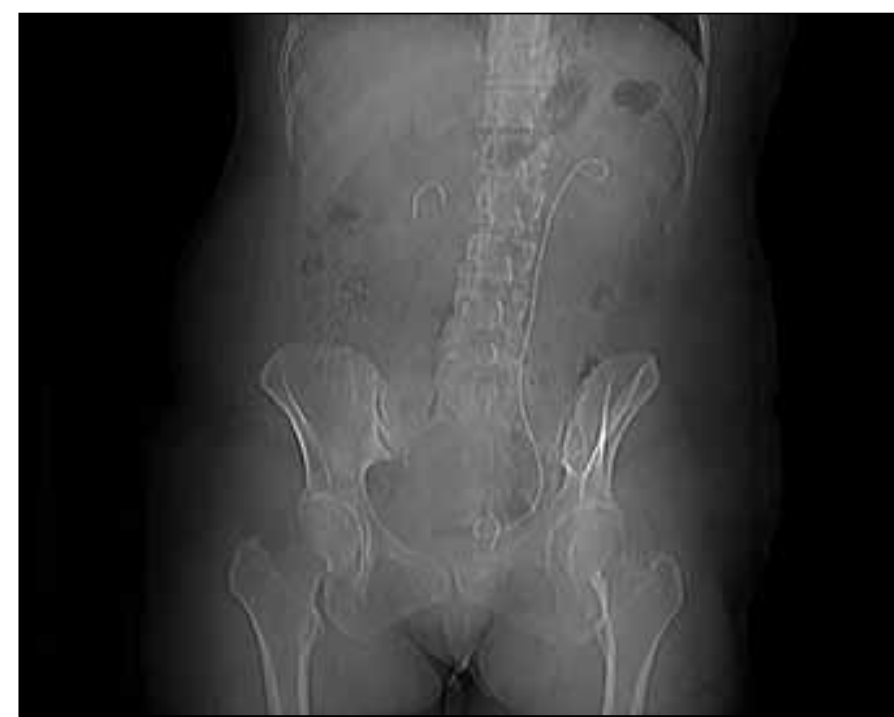

Fig. 1. Computed tomography scout film showing a fragment of stent left at the right renal pelvis and an indwelling left ureteral stent.

diagnosed with obstructive uropathy (creatinine $1.02 \mathrm{mg} / \mathrm{dL}$ ) secondary to left proximal ureterolithiasis $(0.8 \mathrm{~cm})$ and cystolithiasis $(1.5 \mathrm{~cm})$, which was a result of his non-compliant follow-up after an extracorporeal shockwave lithotripsy (ESWL) of left nephrolithiasis a year earlier. He underwent cystoscopy, retrograde pyelogram, ureteroscopy, intracorporeal lithotripsy and cystolitholapaxy. A Fr 6 x 24-cm Tecoflex polyurethane double pigtail ureteral stents (R\&D Tech Inc,
Groton, Massachusetts, USA) was inserted due to complicated ureteroscopy. He was advised to follow-up within 3 months for removal of the stent. The patient followed-up with plain kidney urinary bladder (KUB) x-ray showing an intact indwelling left ureteral stent (Fig. 3). He was advised to remove the J stent; yet due to his financial constraints, he deferred procedure and lost to follow-up.

Now, he presented with persistent dysuria and left flank pain, which he attributed to stent irritation. On physical examination, there was left costovertebral tenderness; other systemic examinations were unremarkable. Routine biochemical parameters were normal: urinalysis revealed proteinuria $(100 \mathrm{mg} / \mathrm{dL})$, nitrites and leukocyte esterase positive (+3), hematuria RBC (1070/hpf), pyuria white blood cells (WBC) (425/hpf) and bacteruria (5465/hpf). Urine culture revealed Escherichia coli about 50,000 cfu/mL. Plain KUB x-ray revealed a fragmented left ureteral stent, point of fracture noted at the proximal renal end (Fig. 3). He was hospitalized, administered culture-guided IV antibiotics, and underwent video-assisted ureterscopy using Fr 9 semi-rigid ureteroscope. Upon retrieval of the stent fragments, the ureteral mucosa was diffusely edematous and erythematous and more extensive at proximal ureteral segment. Ureteral intubation was done to alleviate ureteral edema (Table 1). Open ureteral catheter was removed after 48 hours. He recovered well and was discharged on POD 2.

\begin{tabular}{|c|c|c|c|c|}
\hline & Case 1 & Case 2 & Case 3 & Case 4 \\
\hline Age/Sex & $31 / \mathrm{F}$ & $62 / \mathrm{M}$ & $41 / \mathrm{M}$ & $48 / F$ \\
\hline $\begin{array}{l}\text { Prior indication for } \\
\text { insertion of stent }\end{array}$ & $\begin{array}{c}\text { Promote ureteral healing post } \\
\text { ureterolithotomy }\end{array}$ & $\begin{array}{l}\text { Relief of ureteral } \\
\text { edema }\end{array}$ & $\begin{array}{l}\text { Bypass of ureteral } \\
\text { obstruction sec to } \\
\text { ureterolithiasis }\end{array}$ & $\begin{array}{l}\text { Bypass extrinsic ureteral } \\
\text { compression }\end{array}$ \\
\hline $\begin{array}{l}\text { Biomaterial stent } \\
\text { composition }\end{array}$ & Tecoflex Polyurethane & $\begin{array}{l}\text { Tecoflex } \\
\text { Polyurethane }\end{array}$ & $\begin{array}{l}\text { Tecoflex } \\
\text { Polyurethane }\end{array}$ & Tecoflex Polyurethane \\
\hline $\begin{array}{l}\text { Ureteral stent calibre } \\
\text { and length }\end{array}$ & Fr $6 \times 26 \mathrm{~cm} \mathrm{\# 2}$ & $\operatorname{Fr} 6 \times 24 \mathrm{~cm}$ & $\operatorname{Fr} 6 \times 24 \mathrm{~cm}$ & Fr $7 \times 24 \mathrm{~cm} \# 2$ \\
\hline Indwelling period of time & 5 months & 6 months & 11 months & 5 months \\
\hline Presenting symptoms & $\begin{array}{l}\text { Stenturia, gross hematuria, } \\
\text { flank pain, dysuria }\end{array}$ & Dysuria, flank pain & Hematuria, flank pain & $\begin{array}{c}\text { Stenturia, }{ }^{*} \text { gross hematuria, } \\
\text { dysuria, low back pain }\end{array}$ \\
\hline Physical exam findings & $\begin{array}{l}\text { Low grade fever, right CVA } \\
\text { tenderness }\end{array}$ & $\begin{array}{l}\text { Left CVA } \\
\text { tenderness }\end{array}$ & $\begin{array}{l}\text { Mild right CVA } \\
\text { tenderness }\end{array}$ & Bilateral CVA tenderness \\
\hline Remarkable laboratories & $\begin{array}{c}\text { UTI on urinalysis, Enterococcus } \\
\text { sp on urine Culture }\end{array}$ & $\begin{array}{l}\text { UTI on urinalysis, E. } \\
\text { Coli on urine CS }\end{array}$ & $\begin{array}{l}\text { UTI on urinalysis, E. } \\
\text { Coli on urine CS }\end{array}$ & E. Coli on Urine CS \\
\hline Mode of stent retrieval & $\begin{array}{l}\text { Ureteroscopy, foreign body } \\
\text { grasper }\end{array}$ & $\begin{array}{l}\text { Ureteroscopy, } \\
\text { foreign body } \\
\text { grasper }\end{array}$ & $\begin{array}{l}\text { Ureteroscopy, foreign } \\
\text { body grasper }\end{array}$ & $\begin{array}{l}\text { Ureteroscopy, foreign body } \\
\text { grasper and endonephroscopy } \\
\text { percutaneous }\end{array}$ \\
\hline Stent findings & $\begin{array}{l}\text { Moderately encrusted, } \\
\text { breakage line along stent side } \\
\text { hole at proximal renal end, } \\
\text { right, weak point line on the left } \\
\text { distal bladder end side hole }\end{array}$ & $\begin{array}{l}\text { Moderately } \\
\text { encrusted, breakage } \\
\text { line along stent side } \\
\text { hole at proximal } \\
\text { renal end }\end{array}$ & $\begin{array}{l}\text { Severely encrusted, } \\
\text { breakage line along } \\
\text { stent side hole at } \\
\text { distal bladder end }\end{array}$ & $\begin{array}{l}\text { Slightly encrusted with } \\
\text { breakage lines along stent side } \\
\text { holes, right renal proximal end } \\
\text { and left distal bladder end }\end{array}$ \\
\hline
\end{tabular}




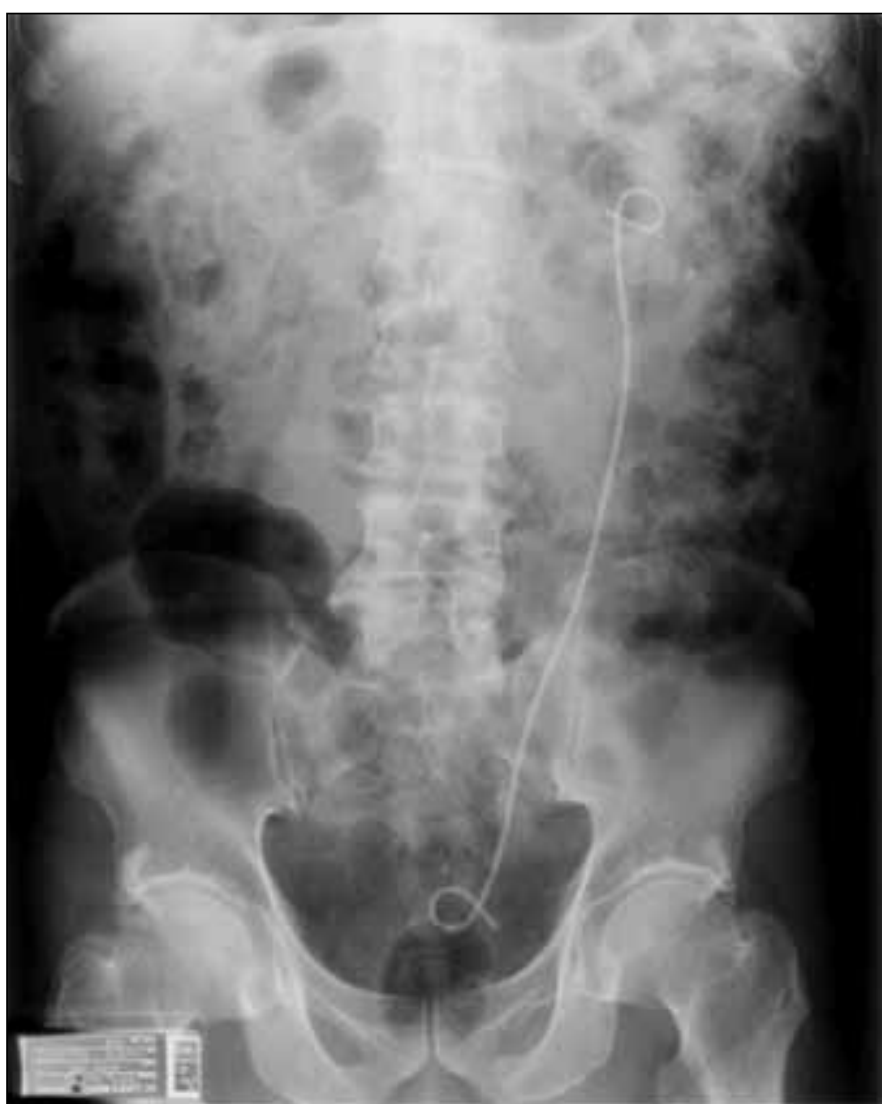

Fig. 2. Kidney, ureter, bladder x-ray showing an indwelling left ureteral stent in place.

\section{Case 3}

A 41-year-old male without medical comorbidities or prior open surgeries consulted due to 2 weeks of right flank pain and occasional hematuria. Eleven months prior to consult, he was diagnosed with obstructive uropathy (creatinine $1.0 \mathrm{mg} / \mathrm{dL}$ ) right, secondary to right proximal ureterolithiasis $(1.3 \mathrm{~cm})$. He was managed with cystoscopy and retrograde pyelogram; a Fr $6 \times 24-\mathrm{cm}$ Tecoflex polyurethane double pigtail ureteral stents (R\&D Tech Inc, Groton, MA) was inserted at that time to bypass ureteral obstruction. He then had two sessions of ESWL within a month. Two months after, he was diagnosed with pulmonary tuberculosis disease and the ureteral J stent removal was deferred. The patient opted to complete his 9-month treatment regimen.

On this consult, physical examination revealed mild right costovertebral angle tenderness; other systemic examinations were unremarkable. Routine biochemical parameters were normal: urinalysis revealed proteinuria $(30 \mathrm{mg} / \mathrm{dL})$, leukocyte esterase positive (+2); hematuria RBC (60-80/ hpf), pyuria WBC (60-80/hpf) and bacteuria (300/hpf). Urine culture revealed Escherichia Coli about $50000 \mathrm{cfu} / \mathrm{mL}$. A CT stonogram revealed a fragmented right ureteral stent, point of fracture at the distal bladder end (Fig. 4, Fig. 5, Fig.

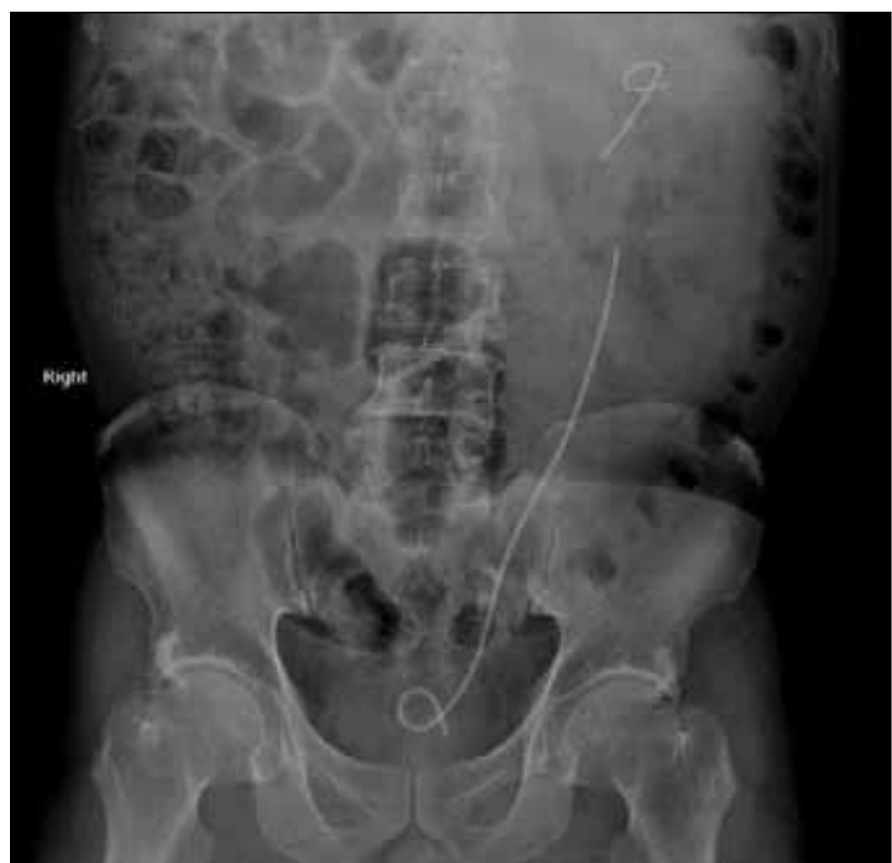

Fig. 3. Kidney, ureter, bladder x-ray showed a fragmented left ureteral stent, with the point of fracture at the proximal renal end.

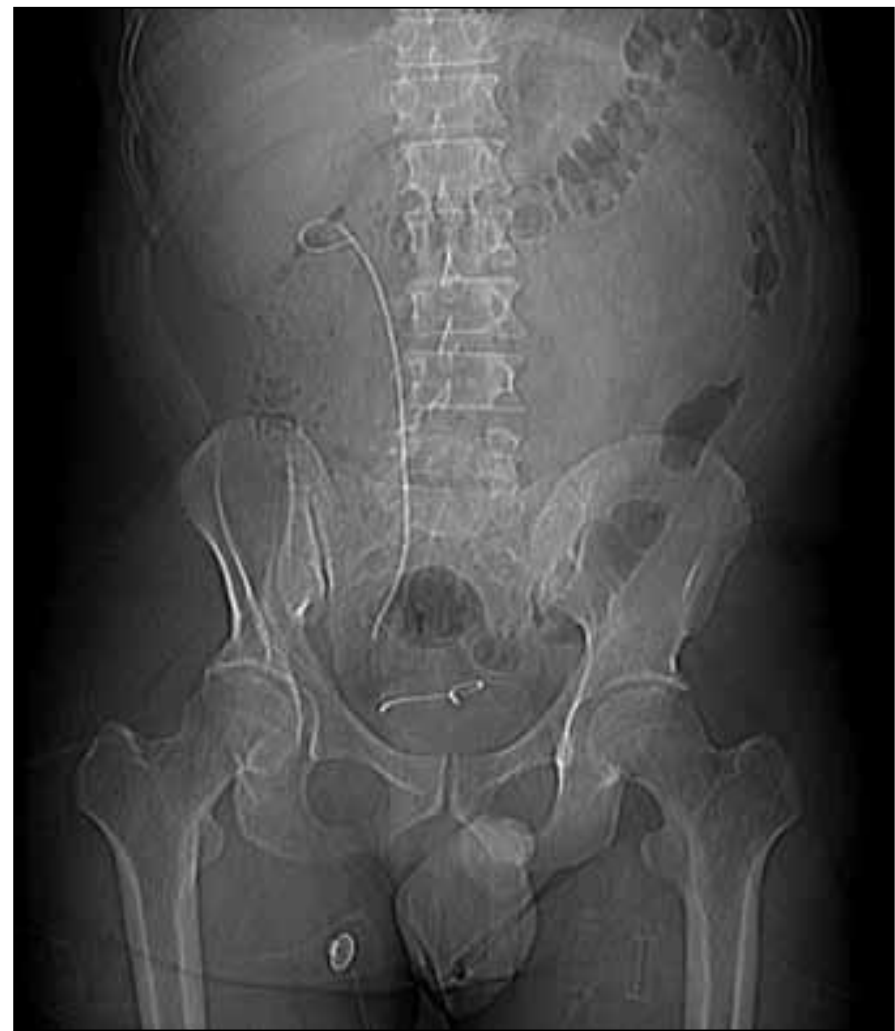

Fig. 4. Computed tomography scout film showing a fragmented ureteral stent point of fracture at the distal bladder end.

6). No hydronephrosis was noted on the right kidney. He was hospitalized, started on culture-guided IV antibiotics, underwent ureterscopy and retrieval of stent fragment using 


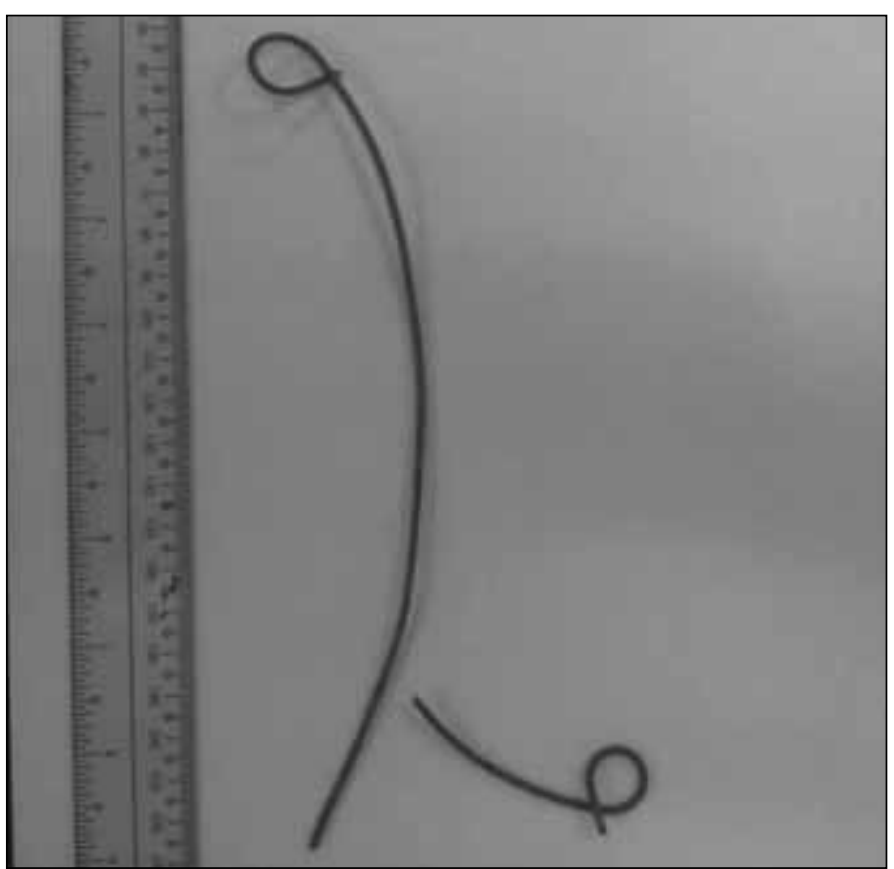

Fig. 5. Actual retrieved fracture stent.

Fr 9 ureteroscope and ureteral foreign body grasper. Intraoperatively, ureteral stent fragment was removed without resistance; the ureteral lumen was mildly edematous (Table 1) (Fig. 7). He recovered well and was discharged on POD 1.

\section{Case 4}

A 48-year-old female with no known medical comorbidities consulted due to complaints of stenturia in a span of 1 month. She had persistent gross hematuria, dysuria and concomitant lower back pain. Five months before, she was diagnosed with obstructive nephropathy bilateral (creatinine $11.39 \mathrm{mg} / \mathrm{dL}$ ), secondary to extrinsic compression (retroperitoneal mass, about $8 \mathrm{~cm}$ and $9 \mathrm{~cm}$ ). She underwent bilateral oophorocystectomy and retroperitoneal mass incision biopsy due to its anatomic difficulty for complete excision; also, cystoscopy and retrograde pyelogram were done. Two Fr $7 \times 24-\mathrm{cm}$ Tecoflex polyurethane double pigtail ureteral stents (R\&D Tech Inc, Groton, Massachusetts, USA) were also inserted bilaterally to bypass ureteral obstruction. She was advised to follow-up for J stent removal within 3 months for ureteral stent replacement; however, she was lost to follow-up.

Now, her physical examination revealed bilateral costovertebral angle tenderness. Other systemic examination was unremarkable. Routine biochemical parameters were normal: urine culture revealed Escherichia Coli about $80000 \mathrm{cfu} /$ $\mathrm{mL}$. A CT stonogram revealed bilaterally fractured stent, a piece of retained right ureteral stent on the right pelvis and a retained segment of left ureteral stent with a missing distal bladder end (Fig. 7). Moderate hydronephrosis was noted

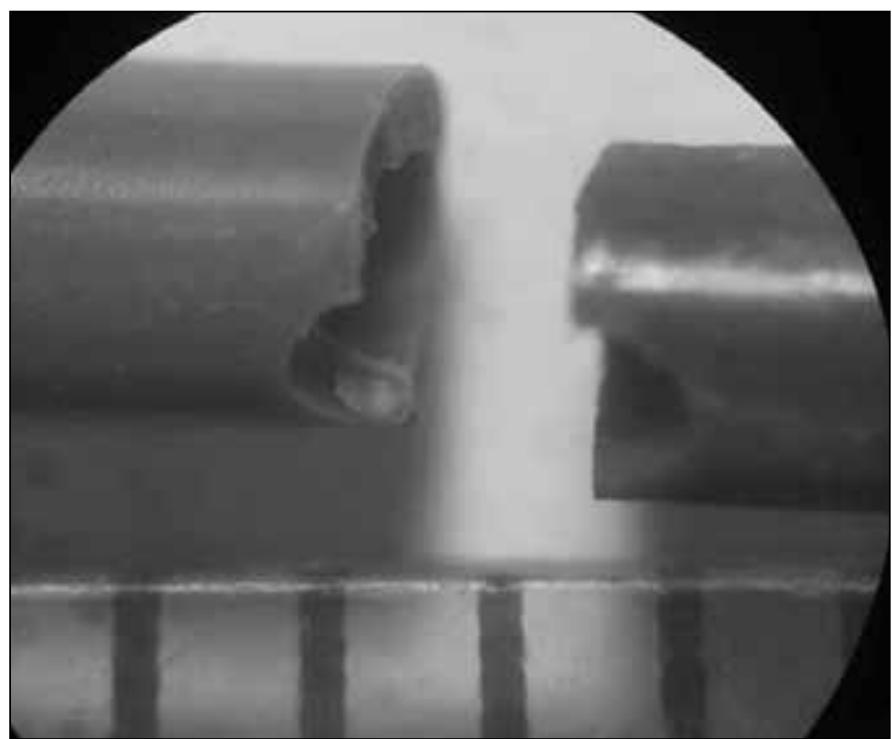

Fig. 6. Microscopic imaging of the stent fragment (magnification $\times 500$ ) showing line of breakage traversing the polyurethane ureteral stent side hole near the distal bladder end.

on the right kidney, while dilated pelvocalyceal system on the left. She was admitted and treated with culture-guided IV antibiotics. The left retained J stent was removed using $\mathrm{Fr} 7$ ureteroscope and ureteral foreign body grasper. The ureteroscope was not able to advance through middle segment of the right ureter due to extrinsic compression of the retroperitoneal mass. The patient underwent endonephroscopy percutaneous retrieval of stent fragment. A superior pole renal access was done under fluoroscopy using a 2-stick technique; a Nephromax balloon dilator was used to dilate the fascia prior to placement of the access sheath. Fr 24 nephroscope was inserted and the retained stent fragment was retrieved under direct visualization. She was retained with a draining nephrostomy tube postoperatively (Table 1) (Fig. 8). She recovered well and was discharged on POD 8.

\section{Discussion}

Ureteral stent placement is common. ${ }^{17-19}$ The ideal biomaterial includes biological inertia, chemical stability in the urine, resistance to infection and encrustation, long-term urinary flow, stability, no discomfort and affordability. ${ }^{19}$ At present, biomaterials commonly used in the urinary tract include polyurethrane, silicone, Silitek, C-Flex, Percuflex and metals, and have their own inherent advantages and drawbacks. ${ }^{18-20}$

Polyurethrane is highly versatile and inexpensive. Its use in ureteral stents increases their luminal urine flow and improves drainage due to large side holes. Polyurethrane is widely used in Asia for different indications. However, like other biomaterials it is associated with several complications. After studying 290 stone patients, El-Faqih and 


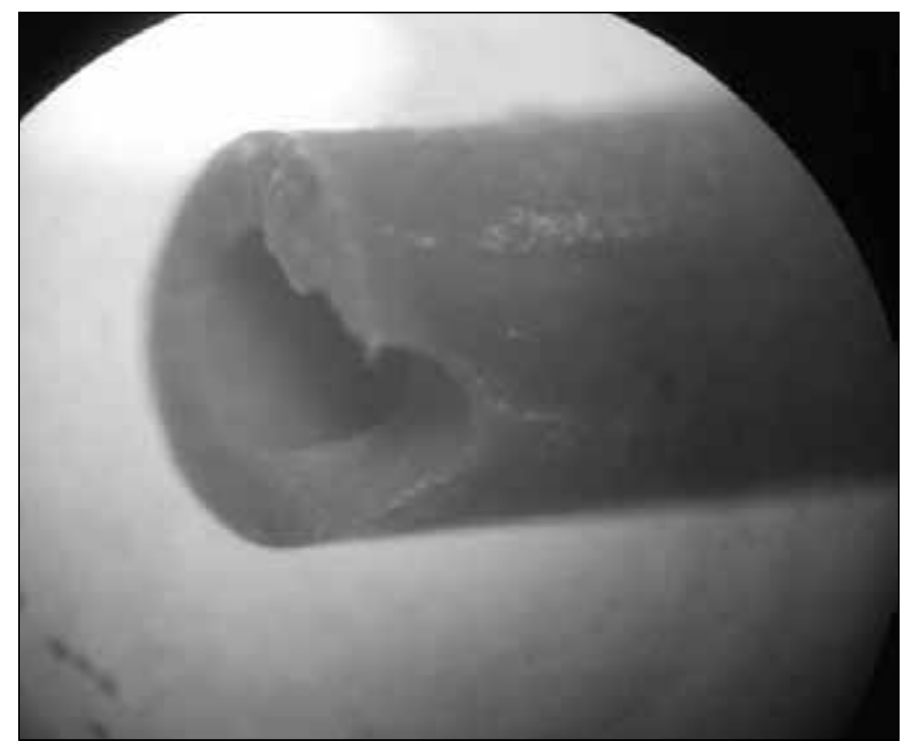

Fig. 7. Second image: microscopic imaging of the stent fragment (magnification $\times 500$ ) showing line of breakage traversing the polyurethane ureteral stent side hole near the distal bladder end.

colleagues noted that when stents are left indwelling for more than 12 weeks, the incident rate of encrustation was $76.3 \%$, stent migration $3.7 \%$, infection $6.7 \%$ and fragmentation $0.3 \% .^{5}$ Spontaneous ureteral stent fragmentation is rare. ${ }^{13,15}$ We present four cases of spontaneous fracture of double J polyurethane ureteral stents; these were all placed for different indications and the patients experienced spontaneous fracture preoperatively.

Forgotten ureteral stents are observed in urologic practice because of poor compliance or failure of the physician to adequately counsel the patient. El-Faqih and colleagues demonstrated that the rate of complication for polyurethane stents indwelling for less than 6 weeks was $9.6 \%$, whereas the rate increased to $47.5 \%$ for stents left for 6 to 12 weeks and even increased to $76.3 \%$ for stents left more than 12 weeks. ${ }^{5}$ The findings were supported by Kumar and colleagues; they found that stents had fragmented into multiple pieces over a mean indwelling time of only 14 weeks. ${ }^{11}$ A common characteristic of our cases was the prolonged indwelling time of the stents, with an average indwelling time of 47 weeks and median time of 20 weeks. When the stent is exposed to different factors in the urine and the urothelium for a long time, it may lead to loss of strength, elasticity and flexibility of the stent; ${ }^{18}$ the degradation of stent polymers leads to loss of tensile strength and hardening of the stent. The optimal indwelling period is at 8 to 16 weeks. $5,6,13,21$ If stents were to be placed for prolonged periods, it is recommended that they are evaluated and changed periodically (8 to 12 weeks), particularly for polyurethane stents or as per manufacturer's instructions. ${ }^{13,21}$

The common presentations in our patients were flank pain with costovertebral angle tenderness, followed by hema-

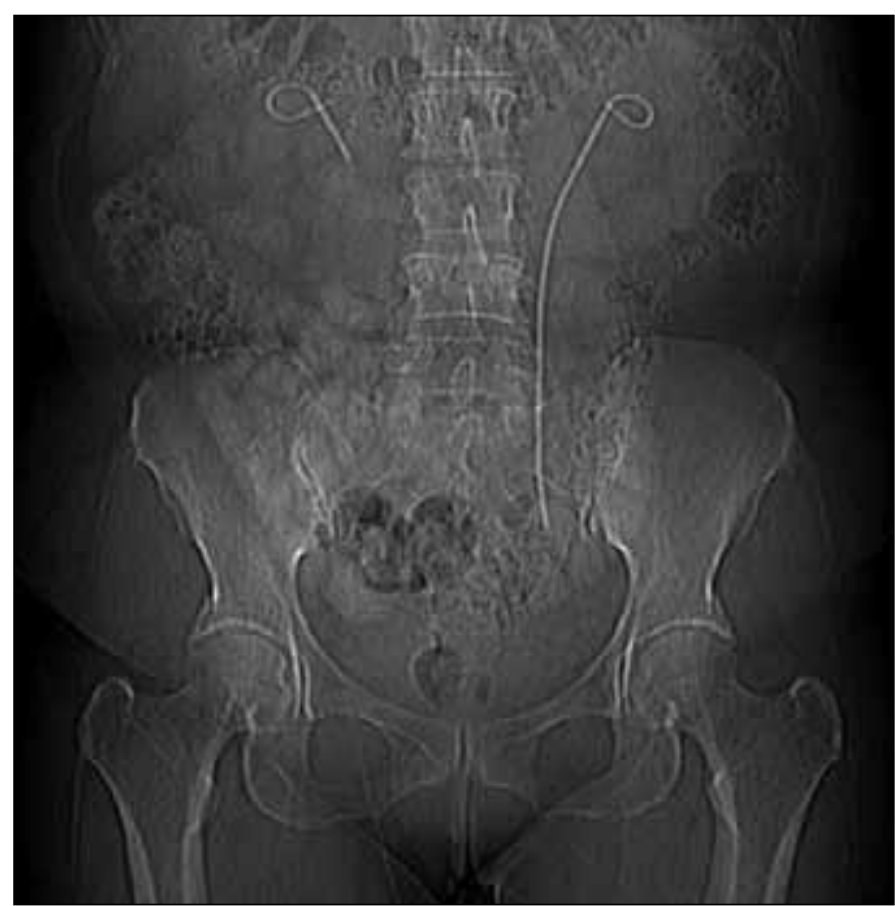

Fig. 8. Computed tomography scout film showing bilateral fractured stent; a piece of retained right ureteral stent on the right pelvis and a retained segment of left ureteral stent with a missing bladder end.

turia, dysuria and stenturia. Similar clinical presentations were reported by other authors., ${ }^{8,9,11-15}$ Various mechanisms have been proposed to explain ureteral stent fragmentation. In most cases of fractured stents, many leukocytes in the urine with or without infection were identified; this leads to depolymerization of biomaterials. ${ }^{7}$ Such findings were also observed in our cases.

Encrustations of the ureteral stents are associated with urinary infection. ${ }^{12}$ Encrustations are often composed of calcium oxalate which is enhanced by rough surfaces, catheter holes and edges (major characteristics of polyurethane stents). ${ }^{19}$ Singh and colleagues noted that the most dense and thickened encrustations were seen in the upper curl with minimal encrustation in the lower curl, which may be due to the effective peristalsis in the lower and intramural part of the stent. ${ }^{22}$ Due to the encrustations, both ends of the stent were retained in situ and the central shaft may be degraded and vanished due to hostile urine environment cause by infections. ${ }^{15}$

The aging of the stent may lead to its mechanical failure. Zisman and colleagues demonstrated that stent material changed from ductile to brittle during exposure to a harsh urine environment. ${ }^{8}$ The accelerated aging is an important factor leading to early mechanical failure of poor biodurable polymers, such as polyurethane biomaterials. ${ }^{23}$ With continuous mechanical failure, stent fragmentation was also common in areas allowed to kink during stent insertion. ${ }^{9}$ Fragmentation of polyurethrane stent is 4 times as 


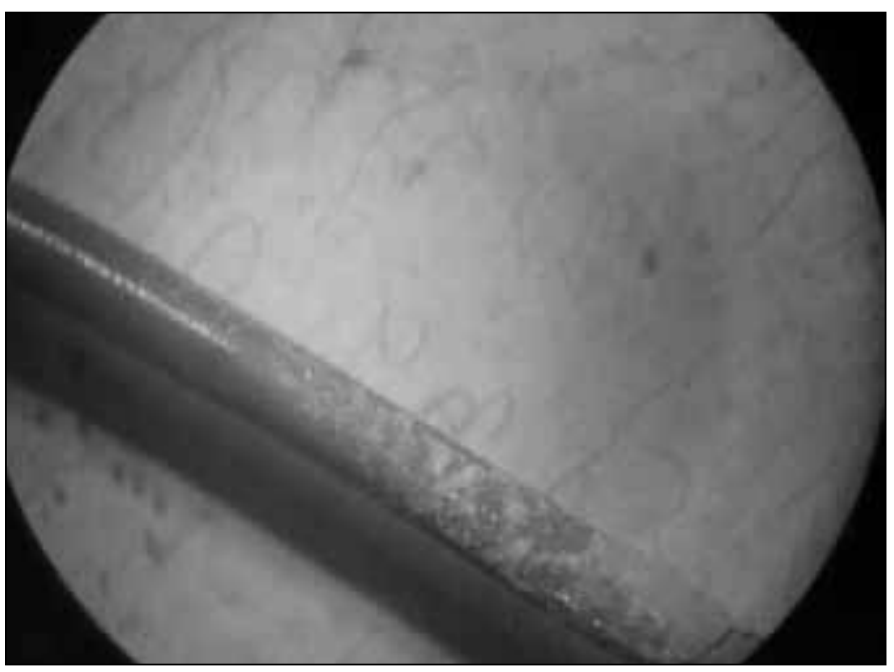

Fig. 9. Removed polyurethane ureteral stent fragments were noted moderately encrusted and breakage lines are noted along the stent side hole.

frequent as silicone and other biomaterial stents. Fracture of the polyurethane stents may also be caused by repeated mechanical stress, especially along the side holes. ${ }^{24}$ It has been reported that most fracture points were also along the drainage holes; therefore, the incidence of ureteral stent fracture can be decreased by eliminating these holes. ${ }^{20}$ In our cases, most fractures were at the proximal renal end and, on the microscopic finding of the retrieved stents, the breakage line traverses the ureteral stent side holes. Upon preoperative radiological workup of our patients, we found that most of the inserted polyurethane ureteral stents lengths were longer than appropriate; this may have led to an increase in mechanical stress to the stent.

Generally, transurethral intervention is enough to remove the bladder stents; this was applied to our cases and only one patient needed a percutaneous endorenoscope to retrieve a proximal renal ureteral stent fragment. Retrieving a proximally fragmented double-J ureteral stent can be frustrating and technically challenging. In previous reports, ureterorenoscopy and percutaneous procedures were used to remove fractured stents in the renal pelvis, ${ }^{17}$ while midureteral stents fragments can be removed using a stone basket under fluoroscopic guidance. ${ }^{9}$ Endourological techniques promotes the preservation of renal function and would render the patient stent-free. ${ }^{12}$

It is better to prevent the occurrence of fracture stents rather than to struggle in removing them. Timely cystoscopic removal or exchange of the ureteral catheter would minimize stent calcification and fragmentation. Most manufacturers of polyurethrane stents recommend changing them every 2 to 3 months. ${ }^{13}$ Poor compliance is the most important risk factor for stent fragmentation. This can be prevented by using a computerized registry system to track patients, using a distal traction suture to a ureteral stent and using a ureteral catheter. ${ }^{9,17,25}$ These methods have been demon-

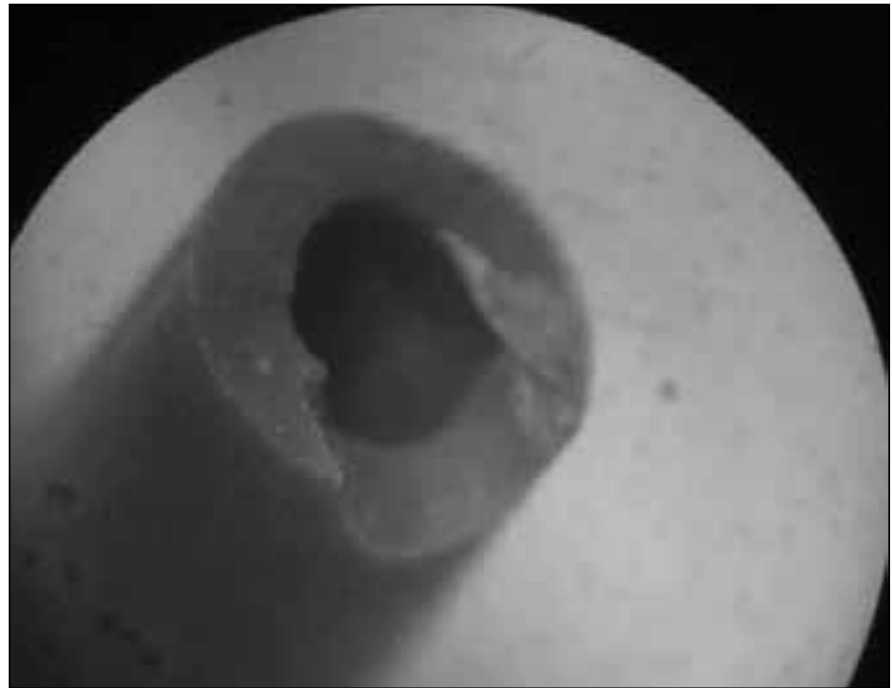

Fig. 10. Second image: Removed polyurethane ureteral stent fragments were noted moderately encrusted and breakage lines are noted along the stent side hole.

strated to lower the incidence of overdue ureteral stents from $12.5 \%$ to $1.2 \%$ over a year. ${ }^{26}$ Synthesized poly-L,D-lactide ureteral stents are able to dissolve in 6 to 12 weeks without significant obstruction during the biodegradation process. ${ }^{19}$

A hostile urine environment may accelerate the polymer degradation and enhance encrustation leading to stent fragmentations. Therefore, this risk may be minimized by controlling urinary tract infections, ensuring good hydration, instituting dietary modifications, minimizing complications of chronic renal failure, and administering thiazide, xanthine-oxidase inhibitors and potassium citrate in patients with idiopathic recurrent calcium oxalate urolithiasis. ${ }^{13,21}$ Also, choosing the correct stent length may reduce the risk of stent fracture. ${ }^{24}$

\section{Conclusion}

We present four cases of spontaneous fracture of indwelling polyurethane ureteral stents. Strategies to prevent stent fracture include: decreasing the time of the indwelling stent by increasing patient follow-up using a computerized patient registry to track patients; instituting dietary modifications to decrease the hostile urine environment of the urine and encouraging hydration and control of urinary tract infection. Using the right stent length for each patient would also reduce the risk of stent fracture.

Competing interests: None declared.

This paper has been peer-reviewed. 


\section{References}

1. Zimskind PD, Kelter TR, Wikerson SL. Clinical use of long-term indwelling silicone rubber ureteral splints inserted cystoscopically. J Urol 1967;97:840-4.

2. Liu JS, Hrebinko RL. The use of two ipsilateral ureteral stents for relief of ureteral obstruction from extrinsic compression. J Urol 1998;159:179-81. http://dx.doi.org/10.1016/S0022-5347(01)64050-3

3. Damiano R. Olivia A, Espositio C, et al. Early and late complications of double pigtail ureteral stent. Urol Int 2002;69:136-40. http://dx.doi.org/10.1159/000065563

4. Kuyumcuoglu $U$, Ervildirim $B$, Tuncer $M$, et al. Effectiveness of medical treatment in overcoming the ureteral double-J stent related symptoms. Can Urol Assoc J 2011;Sep 8:1-4 Epub ahead of print.

5. El-Faqih SR, Shamsuddin AB, Chakrabarti $A$, et al. Polyurethane internal ureteral stents in treatment of stone patients: Morbidity related to indwelling times. J Urol 1991;146:1487.

6. Schulze KA, Wettlaufer JN, Oldani $G$. Encrustation and stone formation: complication of indwelling ureteral stents. Urology 1985;25:616-9. http://dx.doi.org/10.1016/0090-4295(85)90293-6

7. Ilker Y, Turkeri L, Dillioglugil 0 , et al. Spontaneous fracture of indwelling ureteral stents in patients treated with extracorporeal shock wave lithotripsy: two case reports. Int Urol Nephrol 1996;28:15-9. http:// dx.doi.org/10.1007/BF02550132

8. Zisman A, Siegel YI, Siegmann A, et al. Spontaneous ureteral stent fragmentation. J Urol 1995;153:71821. http://dx.doi.org/10.1016/S0022-5347(01)67697-3

9. Kilciler $M$, Erdemir $F$, Bedir $S$, et al. Spontaneous ureteral stent fragmentation: a case report and review of the literature. Kaohsiung J Med Sci 2006;22:363-6. http://dx.doi.org/10.1016/S1607$551 \times(09) 70324-9$

10. Mardis HK, Kroeger RM. Ureteral stents. Materials. Urol Clin North Am 1988;15:471-9.

11. Kumar $M$, Aron $M$, Agarwal AK, et al. Stenturia: an unusual manifestation of spontaneous ureteral stent fragmentation. Urol Int 1999;62:114-6. http://dx.doi.org/10.1159/000030370

12. Monga $M$, Klein $E$, Castañeda-Zúñiga WR, et al. The forgotten indwelling ureteral stent: a urological dilemma. J Urol 1995;153:1817-9. http://dx.doi.org/10.1016/S0022-5347(01)67319-1

13. Singh V, Gupta A. Stenuria: A Rare Complication of Indwelling Ureteral Stent. Urol J 2009;6:226-7.

14. Adsan 0 , Guner E, Ozturk B, et al. Spontaneus Fragmentation of a Double I Stent. Int Urol and Nephrol 1997;29:307-11. http://dx.doi.org/10.1007/BF02550927
15. Gupta R, Modi P, Rizvi J. Vanishing Shaft of a Double -J stent. Urol J 2008:5:277-9.

16. Dindo D, Demartines N, Clavien PA. Classification of surgical complications: a new proposal with evaluation in a cohort of 6336 patients and results of a survey. Ann Surg 2004;240:205-13. http://dx.doi. org/10.1097/01.sla.0000133083.54934.ae

17. Ahallal Y, Khallouk A, El Fassi MJ, et al. Risk Factor Analysis and Management of Ureteral Double-J Stent Complications. Rev Urol 2010;12:e147-e151.

18. Arshad M, Shah SS, Abbasi MH. Applications and complications of polyurethane stenting in urology. J Ayub Med Coll Abbottabad 2006;18:69-72.

19. Beiko DT, Knudsen BE, Watterson JD, et al. Urinary tract biomaterials. J Urol 2004;171:2438-44. http:// dx.doi.org/10.1097/01.ju.0000125001.56045.6c

20. Gorman SP, Jones DS, Bonner MC, et al. Mechanical Performance of polyurethrane ureteral stents in vitro and ex vivo. Biomaterials 1997;18:1379-83. http://dx.doi.org/10.1016/S0142-9612(97)00070-7

21. Somers W. Management of forgotten retained indwelling ureteral stents. Urology 1996;47:431-5. http:// dx.doi.org/10.1016/S0090-4295(99)80468-3

22. Singh I, Gupta NP, Hemal AK, et al. Severely encrusted polyurethane ureteral stents: management and analysis of potential risk factors. Urology 2001;58:526-31. http://dx.doi.org/10.1016/S00904295(01)01317-6

23. Richter $S$, Ringel $A$, Shalev $M$, et al. The indwelling ureteric stent: a 'friendly' procedure with unfriendly high morbidity. BJU Int 2000;85:408-11. http://dx.doi.org/10.1046/i.1464-410x.1998.00543.xi1

24. el-Sherif $A$. Fracture of polyurethrane double pigtail stents: an in vivo retrospective and prospective fluoroscopic study. Br J Urol 2008;76:108-14.

25. Lam JS, Gupta M. Tips and Tricks for the management of retained ureteral stents. J Endourol 2002;16:73342. http://dx.doi.org/10.1089/08927790260472881

26. Ather MH, Talati J, Biyabani R. Physician Responsibility for removal of implants: The case for a computerized program for tracking overdue double J stents. Techn Urol 2000;6:189-92.

Correspondence: Dr. Michael Erlano Chua, Institute of Urology, St. Luke's Medical Center, 279 E. Rodriguez Sr. Blud. Cathedral Heights, Quezon City, 1102 Philippines; fax: $06327231199 ;$ auhc_ekim@yahoo.com 